\title{
Espécies de Parmotrema (Parmeliaceae, Ascomycetes liquenizados) com ácidos graxos ou atranorina medulares do litoral centro-sul do Estado de São Paulo
}

\author{
Marcelo Pinto Marcelli ${ }^{1,2}$ e Michel Navarro Benatti ${ }^{1}$
}

Recebido: 16.07.2009; aceito: 28.01.2010

\begin{abstract}
Species of Parmotrema (Parmeliaceae, lichenized Ascomycetes) with medullar fatty acids or atranorin in the center-south coast of São Paulo State). In a survey of the species pertaining to genera of large parmelioid lichens occurring in the coastal areas of the center-south coast of São Paulo State, Brazil, four species of Parmotrema A. Massal. with medullar fatty acids (P. ciliiferum, $P$. cf. cryptoxanthoides, P. melanothrix, and P. praesorediosum) and one containing medullar atranorin (P. mordenii) were found. Identification key, descriptions, commentaries, and illustrations based on collected material are provided for these species.
\end{abstract}

Key words: fatty acids, mangrove, Parmotrema, restinga

RESUMO - (Espécies de Parmotrema (Parmeliaceae, Ascomycetes liquenizados) com ácidos graxos ou atranorina medulares do litoral centro-sul do Estado de São Paulo). O levantamento das espécies pertencentes aos gêneros de grandes parmélias do litoral centro-sul do Estado de São Paulo revelou a ocorrência de quatro espécies de Parmotrema A. Massal. com ácidos graxos medulares (P. ciliiferum, $P$. cf. cryptoxanthoides, $P$. melanothrix e $P$. praesorediosum) e uma com atranorina medular (P. mordenii). São apresentados chave de identificação, descrições detalhadas, comentários e ilustrações baseadas no material coletado.

Palavras-chave: ácidos graxos, manguezal, Parmotrema, restinga

\section{Introdução}

O gênero Parmotrema A. Massal. caracteriza-se pelos talos com lobos de ápices largos e arredondados (maiores que $0,5 \mathrm{~cm}$, com freqüência ultrapassando 2 ou $3 \mathrm{~cm}$ de largura), pela ausência de pseudocifelas (poros com extravasamento de hifas medulares), ocorrência frequiente de cílios marginais, ampla zona marginal do córtex inferior nua, rizinas geralmente simples, e ascósporos elipsóides de paredes espessas (Brodo et al. 2001, Nash \& Elix 2002). Mais de trezentas espécies são conhecidas em todo o mundo (Nash \& Elix 2002), das quais aproximadamente um terço é citado para o Brasil (Marcelli 2005).

As espécies apresentadas neste trabalho possuem como característica principal a completa ausência de reações positivas à testes de coloração na medula, pela presença somente de ácidos graxos medulares, ou no caso de P. mordenii (Hale) Hale apenas uma reação positiva $(\mathrm{K}+$ amarela), devido a presença incomum da substância atranorina, normalmente encontrada apenas nos córtices.

A área abrangida por esta pesquisa e seus respectivos dados geográficos, climáticos e de substratos encontrados na região são descritos em Benatti \& Marcelli (2008). Ela está localizada no litoral centro-sul do Estado de São Paulo, entre as municipalidades de Bertioga e Cananéia.

\section{Material e métodos}

Foram analisadas amostras de coletas recentes e dos últimos 30 anos em todos os municípios da Baixada Santista localizados no litoral centro-

1. Instituto de Botânica, Caixa Postal 3005, 01061-970 São Paulo, SP, Brasil

2. Autor para correspondência: mpmarcelli@msn.com 
sul do Estado de São Paulo, situados abaixo do trópico de Capricórnio e compreendidos entre as municipalidades de Bertioga $\left(46^{\circ} 08^{\prime} 03^{\prime \prime} \mathrm{W}\right.$, $23^{\circ} 51^{\prime} 17^{\prime \prime}$ ) e Cananéia (475' $\left.33^{\prime \prime} \mathrm{W}, 2^{\circ} 00^{\prime} 53^{\prime \prime} \mathrm{S}\right)$.

A metodologia utilizada encontra-se descrita em Benatti \& Marcelli (2008). O material foi coletado e identificado conforme a metodologia em Fink (1905), Galloway $(1985,2007)$ e Hale (1979). Foram realizadas excursões pontuais de coleta a várias localidades urbanas e naturais de todos os municípios da região, tendo sido obtidas amostras de todos os ecossistemas costeiros que compõem a localidade de estudo, que foram acrescentadas às amostras obtidas nas últimas décadas.

A metodologia de análises químicas utilizadas seguiu Asahina \& Shibata (1954), Walker \& James (1980), White \& James (1985), Huneck \& Yoshimura (1996), Bungartz (2001) e Orange et al. (2001), com pequenas mudanças ou adaptações. Foram feitas análises por testes de coloração e por cromatografia em camada delgada (CCD) em solvente $\mathrm{C}$.

Embora sejam discutidos os aspectos mais relevantes pertinentes a cada uma das espécies encontradas, outras comparações e detalhes podem ser encontrados em Benatti (2005).

\section{Resultados}

No litoral centro-sul do Estado de São Paulo foram encontradas quatro espécies de Parmotrema com ácidos graxos medulares, e uma em que a única substância detectada na medula é atranorina, normalmente uma substância cortical. Há apenas um trabalho brasileiro que descreve uma espécie deste grupo, P. melanothrix (Montagne) Hale (Eliasaro \& Donha 2003). Para o Estado de São Paulo e alguns outros estados, há trabalhos estrangeiros com as descrições originais de $P$. ciliiferum Hale (Hale 1990) e de P. cryptoxanthoides (Kurokawa) Hale ex DePriest \& B. Hale (Kurokawa 1974), enquanto que Vainio (1890), Lynge (1914) e Hale (1965) citaram material brasileiro de $P$. melanothrix e $P$. praesorediosum (Nyl.) Hale em seus trabalhos, estas últimas citadas (não descritas) apenas por Marcelli (1991) para o Estado de São Paulo.

Como P. mordenii é aceita por alguns autores como sinônimo de $P$. praesorediosum devido à similaridade morfológica apesar de apresentar atranorina medular, ela esta sendo incluída no estudo das espécies contendo ácidos graxos.

Espécies tratadas neste artigo foram mencionadas e/ou descritas para o Estado de São Paulo apenas em trabalhos não efetivamente publicados, sendo que descrições e comentários sobre estas espécies no Brasil constam principalmente de teses e dissertações (Fleig 1997, Ribeiro 1998, Eliasaro 2001, Benatti 2005, Canêz 2005, Donha 2005, Spielmann 2005, Jungbluth 2006).

Das espécies encontradas, $P$. ciliiferum, $P$. mordenii e $P$. praesorediosum apresentam propagação por sorédios, enquanto que $P$. cf. cryptoxanthoides e $P$. melanothrix não formam propágulos vegetativos.

Foram encontrados ascósporos somente nos apotécios de espécimes de $P$. melanothrix e $P$. praesorediosum, enquanto que conídios estavam presentes em espécimes de $P$. ciliiferum, $P$. melanothrix, $P$. mordenii e $P$. praesorediosum.

Chave para as espécies de Parmotrema com ácidos graxos ou atranorina medulares do litoral centro-sul do Estado de São Paulo

1. Talo saxícola; medula $\mathrm{K}+$ amarelo, com atranorina e ácidos graxos (sorediado) P. mordenii

1. Talo corticícola (a raramente saxícola); medula K-, apenas com ácidos graxos (sorediado ou sem propágulos) 2. Talos sorediados

3. Margens eciliadas; ácidos praesorediósico e protoliquesterínico P. praesorediosum

3. Margens ciliadas; ácidos do grupo constipático P. ciliiferum

2. Talos não sorediados

4. Medula amarelo-clara; ć́lios de ausentes a raros; zona marginal inferior marrom

P. cf. cryptoxanthoides

4. Medula branca; cílios abundantes; zona marginal inferior creme ou variegada P. melanothrix 
Parmotrema ciliiferum Hale, Bibliotheca Lichenologica 38: 112. 1990. Tipo: BRASIL. PARÁ: Base Aérea do Cachimbo, Serra do Cachimbo, $20 \mathrm{Km} \mathrm{N}$ da divisa com Mato Grosso na Rodovia Cuiabá-Santarém, Brako \& Dibben 6073 (holótipo NY n.v.).

Figuras 1a, b

Talo lobado a sublobado, verde acinzentado a pardo quando em herbário, de até $7,0 \mathrm{~cm}$ diâm., submembranáceo, ramulícola; lobos de ramificação irregular, 2,0-7,0 mm larg., de contíguos a pouco sobrepostos lateralmente, às vezes amontoados no centro, elevados, de pouco adpressos a soltos, os ápices subarredondados, de subplanos a subcôncavos, um pouco revolutos principalmente quando lacinulados, as margens subcrenadas, às vezes pouco onduladas, subascendentes, sublacinuladas, de superfície contínua a irregularmente quebrada, lisa a pouco rugosa; lacínulas marginais, mais freqüentes nas partes centrais, planas, 0,5-1,8 $\times 0,3-1,2 \mathrm{~mm}$, simples ou às vezes furcadas, de ápices truncados, lado de baixo creme quando sorediadas ou concolorido à margem inferior; máculas ausentes; cílios negros, de simples a raramente furcados, 0,20-3,50 × ca. 0,05 $\mathrm{mm}$, abundantes, surgindo por toda a margem. Sorais lineares, interrompidos e curtos, às vezes tornandose um pouco irregulares, surgindo geralmente nos ápices de pequenas lacínulas; sorédios subgranulares. Pústulas e isídios ausentes. Medula branca, sem pigmentações. Lado de baixo negro, lustroso, de liso a venado; margem marrom, tornando-se creme em lobos com lacínulas sorediadas, lustrosa, 1,54,0 mm larg., atenuada quando marrom a nítida quando creme, de lisa a muito venada, nua; rizinas concoloridas ao lado de baixo, simples, 0,1-0,5 $\mathrm{mm} \times$ ca. $0,05 \mathrm{~mm}$, escassas, homogeneamente distribuídas, esparsas. Apotécios não encontrados. Picnídios escassos, submarginais, de ostíolo negro; conídios baciliformes, 4,0-5,0 × ca. 1,0 $\mu \mathrm{m}$.

Testes de coloração e substâncias de importância taxonômica: córtex superior $\mathrm{K}+$ amarelo, $\mathrm{UV}-$ (atranorina); medula $\mathrm{K}-, \mathrm{C}-, \mathrm{KC}-, \mathrm{P}, \mathrm{UV}-$ (ácido constipático e outros 4 ácidos graxos não identificados, aparentemente relacionados ao ácido constipático, vistos na placa cromatográfica).

Distribuição: América do Sul. Brasil: PA e SP (Hale 1990, Benatti 2005).

Material estudado: BRASIL. São Paulo: Bertioga, Praia de São Lourenço, mata de pós-dunas em contato com mata de restinga, 15-XI-1977, M.P. Marcelli \& A.E. Luchi 16336 (SP).
Parmotrema ciliiferum é caracterizada pela formação de sorais nos ápices de lacínulas marginais, pelas margens abundantemente ciliadas e pela presença de ácidos graxos do grupo constipático (todos os testes de coloração negativos) na medula. Segundo Hale (1990), esta espécie é a única em Parmotrema contendo esta série de ácidos graxos.

Como ocorre em outras espécies lacinuladas e sorediadas de Parmeliaceae, a zona marginal inferior apresenta uma variação de coloração, que vai do marrom (em lobos jovens distais) a creme (quando em lobos com lacínulas). No espécime encontrado as margens dos lobos tendem a ascender, ficando lateralmente justapostas, contudo sem se sobrepor (apenas no centro do talo os lobos se amontoam um pouco). Os ápices dos lobos ficam às vezes revolutos, mais freqüentemente os lacinulados. $\mathrm{O}$ lado de baixo é pouco rizinado, mesmo nas áreas de mais contato com o substrato, com rizinas curtas que não ultrapassam $0,5 \mathrm{~mm}$ de comprimento.

Dentre as espécies mais próximas, Parmotrema grayanum (Hue) Hale, também ciliada, difere por ser sempre saxícola, coriácea e apresentar ácido protoliquesterínico na medula (Hale 1965, Sipman 2004). Hale (1965) mencionou ainda nos comentários sobre Parmelia grayana (= P. grayanum) que esta espécie tem cílios grossos e aglomerados. Ribeiro (1998) descreveu espécimes de $P$. grayanum (mencionado a espécie pela primeira vez para o continente americano), semelhantes aos estudados por Hale, mas não comentou a rigidez dos talos.

Parmotrema praesorediosum tem as margens mais sinuosas que as de $P$. ciliiferum, além de eciliadas e com sorais marginais lineares que ficam mais espessados, e possui outro conjunto de ácidos graxos medulares (praesorediósico, protopraesorediósico e protoliquesterínico). Outra espécie de morfologia próxima a de $P$. praesorediosum, $P$. mordenii, difere por ser sempre saxícola, também ter margens eciliadas com sorais lineares marginais ou subcapitados, e por apresentar a substância atranorina $(\mathrm{K}+$ amarelo) na medula.

Parmotrema sancti-angeli (Lynge) Hale e Parmotrema subarnoldii (Abbayes) Hale, de margens sorediadas e ciliadas e semelhantes entre si, diferem de $P$. ciliiferum pelos sorais lineares marginais mais longos (e não nos ápices de lacínulas) e pelos cílios ainda mais abundantes e mais longos (frequientemente ultrapassando 5,0 $\mathrm{mm}$ de comprimento). Estas duas espécies diferem ainda por apresentarem reações positivas na medula, devido à presença de 

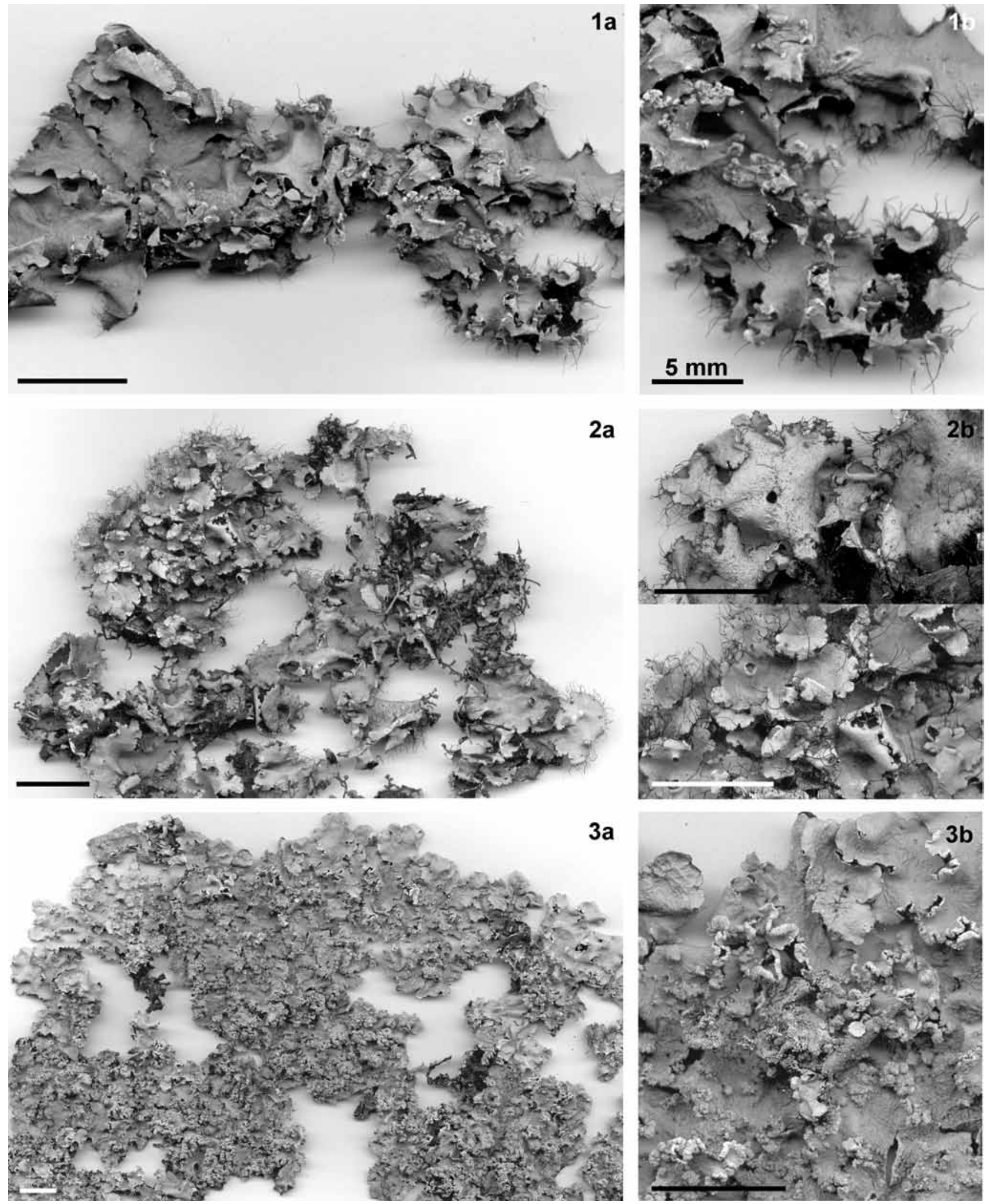

3a

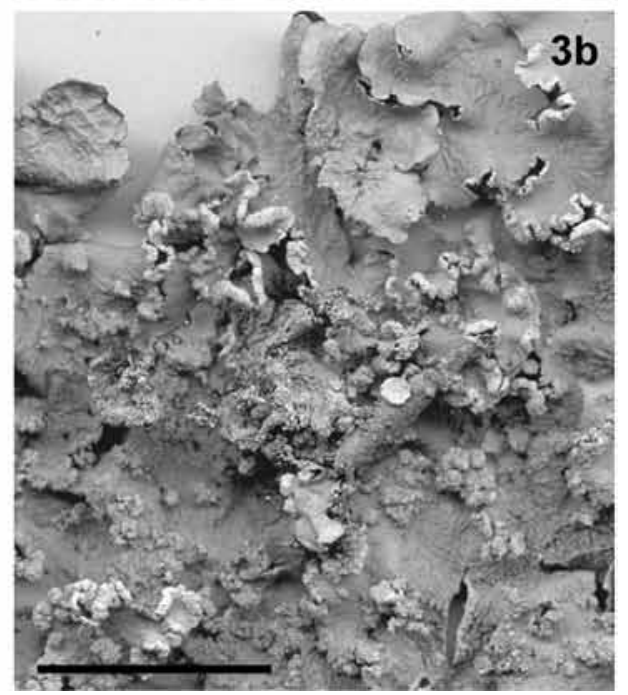

Figuras 1-3. Espécies de Parmotrema do litoral centro-sul do Estado de São Paulo. 1. Parmotrema ciliiferum. a. Hábito. b. Detalhe (Marcelli 16336). 2. Parmotrema melanothrix. a. Hábito. b. Detalhe (em cima - face inferior, Marcelli 1608; embaixo - face superior Marcelli 1609). 3. Parmotema mordenii. a. Hábito. b. Detalhe (Canêz 610). Barras de escala = $1 \mathrm{~cm}$, exceto onde indicado.

Figures 1-3. Species of Parmotrema from the center-south coast of São Paulo State. 1. Parmotrema ciliiferum. a. Habit. b. Detail (Marcelli 16336). 2. Parmotrema melanothrix. a. Habit. b. Detail (above - lower side, Marcelli 1608; below - upper side Marcelli 1609). 3. Parmotema mordenii a. Habit. b. Detail (Canêz 610). Scale bars $=1 \mathrm{~cm}$, except where indicated. 
ácido girofórico em $P$. sancti-angeli $(\mathrm{C}+\mathrm{e} \mathrm{KC}+$ róseos a avermelhados) e de ácido protocetrárico em P. subarnoldii (KC+ róseo e $\mathrm{P}+$ alaranjado). Parmotrema sancti-angeli apresenta ocasionalmente também manchas de pigmento alaranjado $\mathrm{K}+$ avermelhado-escuro na medula. Os conídios nesta espécie são sublageniformes e também mais longos (5,0-7,5 $\mu \mathrm{m}$ compr.) que os conídios baciliformes (4,0-5,0 $\mu \mathrm{m}$ compr.) encontrados em $P$. ciliiferum ou os sublageniformes $(7,0-8,0 \mu \mathrm{m}$ compr.) de $P$. subarnoldii.

Parmotrema indicum Hale difere de $P$. ciliiferum por apresentar na medula ácido girofórico e de norlobaridona (testes $\mathrm{C}+\mathrm{e} \mathrm{KC}+$ róseos a avermelhados, como em $P$. sancti-angeli) segundo Hale (1977), além de ter conídios filiformes mais longos, medindo geralmente $8,0-14,0 \mathrm{~mm}$ de comprimento (Benatti 2005).

Parmotrema cf. cryptoxanthoides (Kurokawa) Hale ex DePriest \& B. Hale, Mycotaxon 67: 203.1998 $\equiv$ Parmelia cryptoxanthoides Kurokawa. Bulletin of the Natural Science Museum of Tokyo 17(4): 297. 1974. Tipo: BRASIL. Paraná: Jardim Paraíso, 9 km a oeste de Curitiba, Kurokawa 8245 (holótipo TNS n.v.).

Ilustração em Benatti \& Marcelli (2010, figura 2a, b

Esta espécie foi previamente abordada em Benatti \& Marcelli (2010), junto ao grupo de espécies caracterizado por apresentar medula pigmentada.

Parmotrema cf. cryptoxanthoides caracterizase pelo talo submembranáceo, de superfície distintamente rugosa com partes quebradiças (especialmente em lobos velhos), medula amareloclara e cílios ausentes a esparsos, com até 1,5 $\mathrm{mm}$ de comprimento (na descrição original com até $2,5 \mathrm{~mm}$ ). A tonalidade amarelada clara vista na medula parece ocorrer ao menos na maior parte de sua extensão. O material está como "cf." devido a não estar fértil e portanto por não terem sido vistos ascósporos ou mesmo conídios, apesar da similaridade em geral das características morfológicas e da coloração e substâncias medulares.

\section{Parmotrema melanothrix (Montagne) Hale,} Phytologia 28(4): 337.1974 三 Parmelia urceolata var. melanothrix Montagne, Annales des Sciences Naturelles, Bot. Ser. 2(2): 372. 1834. Tipo: BRASIL. Local desconhecido, Gaudichaud 89 bis (holótipo P n.v.).

Figuras 2a, b
Talo lobado a sublobado, verde acinzentado a verde pardo quando em herbário, de até $15,0 \mathrm{~cm}$ diâm., subcoriáceo, corticícola ou ramulícola; lobos de ramificação irregular quando mais largos a quase subdicotômica quando mais estreitos, 1,5-6,0(-9,5) mm larg., contíguos mas com freqüência tornandose amontoados nas partes sublobadas, de pouco adnatos a elevados, de pouco adpressos a soltos, os ápices subarredondados a irregulares, de subplanos a subcôncavos, as margens bastante crenadas ou às vezes irregulares, de subplanas a ascendentes, em parte involutas, subonduladas, incisas, pouco sublacinuladas, de superfície contínua, às vezes um pouco irregularmente quebrada, lisa; lacínulas marginais adventícias, ocasionais e irregularmente distribuídas, planas, curtas, 0,4-3,2 × 0,2-0,8 mm, simples ou irregulares, truncadas, lado de baixo mais freqüentemente creme, ou concolorido à margem inferior do talo; máculas distintas, puntiformes a lineares, restritas aos pedicelos e anfitécios dos apotécios; cílios negros, de simples a furcados ou raramente irregulares, $0,10-4,30 \times$ ca. $0,05-0,10$ $\mathrm{mm}$, marginais abundantes sendo mais densos em alguns trechos, em parte com um pigmento cúpreo $\mathrm{K}+$ púrpura. Sorais, pústulas e isídios ausentes. Medula branca, sem pigmentações. Lado de baixo negro, lustroso, de liso a venado ou pouco rugoso; margem em geral creme ou às vezes variegada, sendo marrom somente na porção terminal de alguns lobos ou em alguns poucos lobos jovens distais, pouco lustrosa a opaca, 2,0-12,0 (-20,0) mm larg., nítida quando creme ou apicalmente marrom, a atenuada apenas quando toda marrom, de lisa a pouco rugosa, nua; rizinas concoloridas, de simples a parcialmente furcadas ou irregulares, às vezes aglutinadas, 0,20-2,00 (-3,20 em alguns trechos) $\times 0,05-0,10(-0,25) \mathrm{mm}$, de poucas a freqüentes, agrupadas. Apotécios subcôncavos a côncavos, fendendo e retorcendo conforme envelhecem, 0,511,3 mm diâm., de submarginais a subapicais ou muito raramente laminais, pedicelados, de margem lisa a subcrenada quando jovem tornando-se crenada a denteada, ocasionalmente coronada por primórdios de cílios e tornando-se mais ciliada conforme se desenvolve, anfitécio e pedicelo lisos tornando-se rugosos conforme envelhecem, o pedicelo tornandose verticalmente rugoso e pregueado; disco marrom, não pruinoso, imperfurado; ascósporos elipsóides a raramente subesféricos, 16,5-25,5(-31,5) × 11,5$15,0 \mu \mathrm{m}$, epispório 1,5-2,0(-2,5) $\mathrm{mm}$. Picnídios submarginais a subapicais ou raramente laminais, 

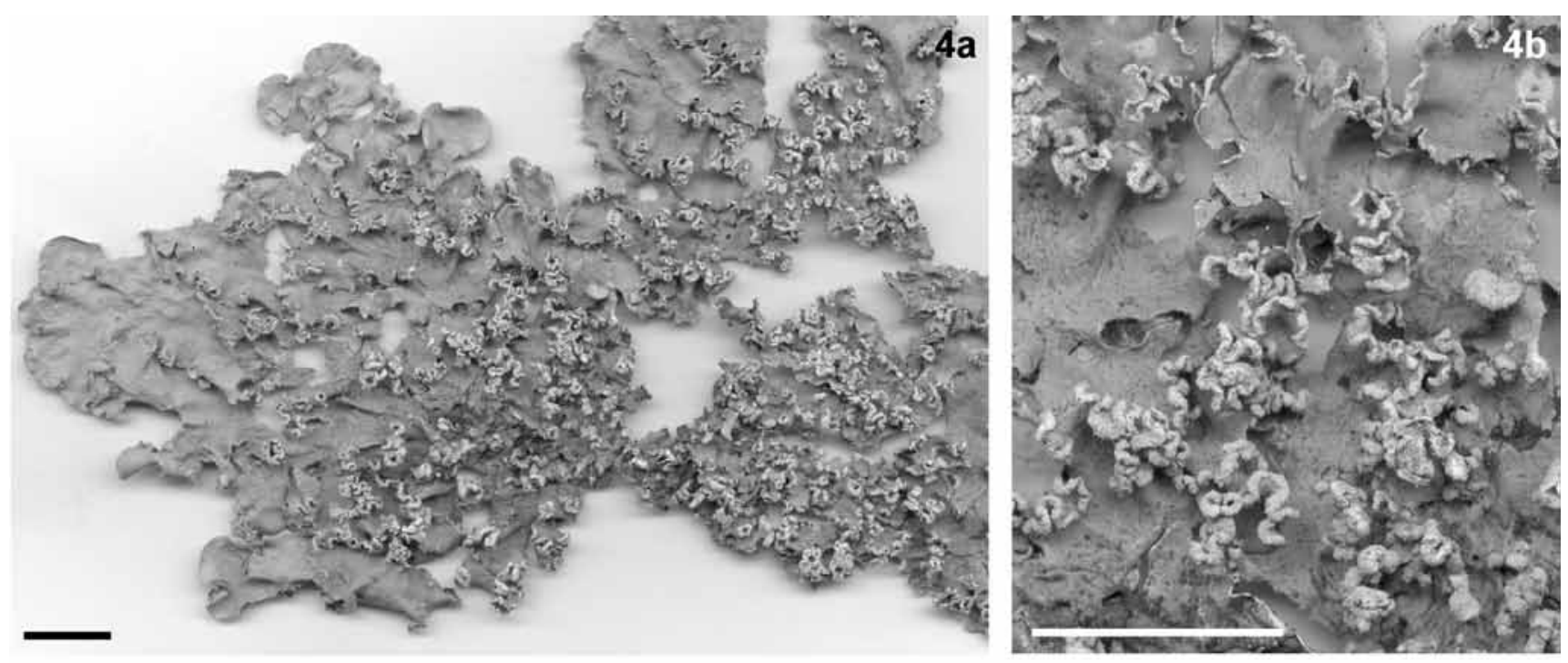

Figura 4. Parmotrema praesorediosum a. Hábito. b. Detalhe (Benatti 1641). Barras de escala $=1 \mathrm{~cm}$.

Figure 4. Parmotrema praesorediosum a. Habit. b. Detail (Benatti 1641). Scale bars $=1 \mathrm{~cm}$, except where indicated.

ostíolo marrom a negro; conídios curto filiformes, $5,0-9,0 \times$ ca. $1,0 \mu \mathrm{m}$.

Testes de coloração e substâncias de importância taxonômica: córtex superior $\mathrm{K}+$ amarelo, UV(atranorina); medula $\mathrm{K}-, \mathrm{C}-, \mathrm{KC}-, \mathrm{P}-, \mathrm{UV}-$ (ácido protoliquesterínico e outro ácido graxo não identificado, detectados em CCD).

Distribuição: Ásia e América do Sul. Brasil: MA, MG, MT, PR, RJ, RS, SC e SP (Vainio 1890, Zahlbruckner 1908, Lynge 1914, Vareschi 1962, Hale 1965, Osorio 1992, Fleig 1997, Ribeiro 1998, Eliasaro 2001, Eliasaro \& Donha 2003, Benatti 2005, Canêz 2005, Spielmann 2005, Divakar \& Upreti 2005, Feuerer 2005, Jungbluth 2006).

Material estudado: BRASIL. São PAULO: Ilha Comprida, Gambôa Nóbrega, parte que deságua no lado continental da ilha, manguezal na margem esquerda da foz da gambôa, 16-II-1982, M.P. Marcelli 1608 (SP); idem, 16-II-1982, M.P. Marcelli 1609 (SP); idem, 16-II-1982, M.P. Marcelli 1610 (SP).

Parmotrema melanothrix é caracterizada pelas margens crenadas densamente ciliadas com cílios longos, ausência de propágulos vegetativos, margem inferior em geral de cor creme e porção apical marrom, rizinas distribuídas em agrupamentos esparsos, apotécios de margens crenadas a denteadas ciliadas, e ausência de reações na medula (todos os testes de coloração negativos) devido à presença somente de ácidos graxos.

Os apotécios nesta espécie, quando muito jovens, têm margens subcrenadas às vezes quase lisas. Primórdios ciliares podem ser observados nestes estágios, o que dá às margens um aspecto de ornamentação coronada parecido com o de apotécios de espécies do gênero Bulbothrix Hale. Conforme o apotécio se desenvolve, estes primórdios vão dando origem a cílios típicos.

Em concordância com as descrições de Fleig (1997), Ribeiro (1998), Eliasaro (2001), Canêz (2005) e Donha (2005), as máculas aqui observadas são restritas somente aos apotécios, sendo geralmente mais fracas na base dos pedicelos, ficando mais distintas nos anfitécios.

As medidas dos ascósporos encontradas estão de acordo com as citadas por Fleig (1997) para o material do Estado do Rio Grande do Sul, inclusive pela ocorrência de alguns poucos ascósporos com mais de $30,0 \mu \mathrm{m}$ (a média geral dos espécimes mal ultrapassa $25,0 \mu \mathrm{m})$, e pela espessura do epispório, entre 1,5-2,0 (-2,5) $\mu \mathrm{m}$.

Outra característica observada aqui e bem explicada por Fleig (1997) foi a coloração das margens inferiores do talo ("zona marginal bege ou branco matizada, geralmente com manchas castanhas junto aos bordos"). Conforme foi observado, a cor da margem inferior é creme em quase toda sua extensão, as partes marrons estando restritas a alguns lobos jovens ou às porções apicais dos lobos maiores.

Outra característica mencionada pela autora que foi constatada é a presença constante de pigmentação cor de cobre $(\mathrm{K}+$ púrpura) em 
grande parte dos cílios, incomum em espécies de Parmotrema que não contenham o ácido alectorônico ( $\mathrm{KC}+$ róseo, $\mathrm{UV}+$ azul-esverdeado) na medula, como por exemplo, Parmotrema mellissii (Dodge) Hale (Hale 1965, Benatti 2005).

Segundo Fleig (1997) e Canêz (2005), $P$. catarinae Hale é semelhante a $P$. melanothrix, porém tem como composto químico medular ácido girofórico $(\mathrm{C}+\mathrm{e} \mathrm{KC}+$ róseos a avermelhados). As autoras não mencionaram a presença de pigmento cor de cobre nos cílios de $P$. catarinae, que é facilmente perceptível nos espécimes de $P$. melanothrix. Fleig (1997) citou que a coloração das margens inferiores de $P$. catarinae varia do castanho ao branco matizado, mas não fez menção a bordas marrons como as de $P$. melanothrix. Pela descrição da autora, deve ocorrer uma forma de alternância entre a coloração marrom e a branca das margens inferiores em $P$. catarinae, sendo que as de $P$. melanothrix são quase que uniformemente da cor creme.

Ribeiro (1998) mencionou material identificado como $P$. catarinae tendo apotécios lisos e eciliados, lobos bastante estreitos (1,0-4,0 mm), margem inferior branca (característica não descrita ou comentada, mas utilizada por ele na chave das espécies de Parmotrema) e rizinas homogêneas e freqüentes. Este material pode tratar-se de uma espécie não descrita próxima a $P$. catarinae, pois tem a mesma química medular (ácido girofórico) e ascósporos de tamanho similar.

Hale (1965) comparou ainda P. melanothrix a $P$. argentinum (Kremp.) Hale (= Parmelia argentina Kremp.), citando que as duas espécies podiam ser separadas pela química medular (presença de ácido alectorônico em $P$. argentinum) e pelo tamanho mediano dos ascósporos $(11,0-22,0 \times 6,0-12,0 \mu \mathrm{m})$ vistos em $P$. argentinum.

Parmotrema eciliatum (Nyl.) Hale assemelhase um pouco a $P$. melanothrix (Benatti 2005), porém difere por não apresentar pigmentação $\mathrm{K}+$ púrpura nos cílios, ter margens em geral mais lisas, zona marginal inferior de coloração marrom com a cor creme normalmente restrita aos lobos com apotécios (sem a borda marrom nos ápices), córtex inferior mais rizinado, apotécios com margens eciliadas, e ácidos medulares do grupo estíctico (K+ amarelo, $\mathrm{P}+$ alaranjado).

Parmotrema mordenii (Hale) Hale, Phytologia 28(4): 337. $1974 \equiv$ Parmelia mordenii Hale, Smithsonian Contributions to Botany 4: 19. 1971.
Tipo: DOMINICA. Norte de Coulibistri, Hale 35649 (holótipo US n.v.).

Figuras $3 \mathrm{a}, \mathrm{b}$

Talo lobado a sublobado, cinza esverdeado a cinza pardo quando em herbário, de até $12,0 \mathrm{~cm}$ diâm., membranáceo a submembranáceo, saxícola; lobos de ramificação irregular, 2,0-8,0 mm larg., de contíguos a pouco sobrepostos lateralmente, em geral muito adnatos e bastante adpressos, os ápices subarredondados, de planos a subplanos ou raramente subcôncavos, as margens lisas a subcrenadas, às vezes um pouco irregulares e elevadas, planas ou em parte involutas e subonduladas, tornando-se freqüentemente subascendentes e mais sinuosas quando sorediadas, de inteiras a incisas, parcialmente sublacinuladas, de superfície contínua nas partes jovens a irregularmente quebrada nas partes velhas, de lisa a pouco rugosa; lacínulas curtas, planas, truncadas, $0,2-0,8 \mathrm{~mm} \times 0,2-0,4 \mathrm{~mm}$, simples, mais freqüentes nas partes mais velhas do talo, raramente surgindo em lobos mais jovens, ocasionalmente misturadas a pequenos lóbulos jovens nas partes velhas, lado de baixo concolorido à margem inferior; máculas ausentes; cílios ausentes. Sorais lineares interrompidos, surgindo nos ápices das lacínulas marginais, freqüentemente coalescendo e às vezes tornando-se irregulares, ou em parte subcapitados, de submarginais a raramente laminais, de aspecto pustular; sorédios subgranulares a granulares. Pústulas (ver sorais) e isídios ausentes. Medula branca, sem pigmentações. Lado de baixo negro, lustroso, de liso a subrugoso ou sutilmente venado, ocasionalmente pouco papilado; margem marrom avermelhada, lustrosa, 1,0-4,5 mm larg., atenuada, de lisa a subrugosa ou subvenada, raramente papilada, nua; rizinas concoloridas, simples a raramente irregulares, $0,20-0,50 \times 0,05-0,15 \mathrm{~mm}$, de escassas a freqüentes tornando-se às vezes abundantes em alguns trechos, muitas vezes aglutinadas, agrupadas. Apotécios côncavos, 0,3-2,1 mm diâm., de laminais a submarginais, de subpedicelados a quase sésseis, eciliados, margem e pedicelo lisos quando jovens, ambos tornando-se eventualmente sorediados; disco marrom-enegrecido nos espécimes estudados, não pruinoso, imperfurado; ascósporos não encontrados (apotécios não desenvolvidos, sem ascos). Picnídios submarginais, de ostíolo negro; conídios sublageniformes a lecitiformes, 4,0-7,5(-8,0) $\times$ ca. $1,0 \mu \mathrm{m}$.

Testes de coloração e substâncias de importância taxonômica: córtex superior $\mathrm{K}+$ amarelo, UV 
(atranorina); medula $\mathrm{K}+$ amarelado, $\mathrm{C}-$, $\mathrm{KC}-$, $\mathrm{P}-$ ou ocasionalmente $\mathrm{P}+$ fraco amarelado, UV(atranorina, ácidos caperático, protoliquesterínico, praesorediósico, protopraesorediósico e mais 2 outros ácidos graxos não identificados na placa cromatográfica).

Distribuição: África, América do Norte, América Central, Caribe e América do Sul. Brasil: RS e SP (Winnem 1975, Jackson \& Hopkins 1980, Hale 1971, Marcelli 1991, Esslinger \& Egan 1995, Benatti 2005, Feuerer 2005, Spielmann 2005, Jungbluth 2006).

Material estudado: BRASIL. São PAUlo: Itanhaém, Bairro Cibratel, costão rochoso entre a Praia dos Sonhos e a Praia de Itanhaém, 10-I-1989, M.P. Marcelli 4185A (SP); idem, 3-IV-1989, M.P. Marcelli et al. 6227(SP). Peruíbe, Reserva Ecológica Juréia-Itatins, Núcleo Guarauzinho, no sopé da Serra do Mar, costão rochoso no lado N, 29-VII-1993, M.P. Marcelli \& O. Yano 23796. São Sebastião, Centro de Biologia Marinha (CEBIMAR) da USP, muro de pedra (arenito) no morro próximo à escada para o auditório, 18-III-1988, M.P. Marcelli 2060 (SP); idem, Ponta do Baleeiro, lado sul do costão rochoso, 19-III-1988, M.P. Marcelli 2234 (SP); idem, 19-III1988, M.P. Marcelli 2238 (SP); idem, 19-III-1988, M.P. Marcelli 2239 (SP). Ubatuba, Ilha Anchieta, Praia das Palmas, costão rochoso do Saco Grande, 23-XI-2003, A.A. Spielmann et al. $587 b$ (SP); idem, sobre rocha granítica exposta ao sol, 23-XI-2003, L.S. Canêz \& A.A. Spielmann 603 (SP); idem, 23-XI2003, I.S. Canêz \& A.A. Spielmann 610 (SP).

Parmotrema mordenii é caracterizada pelo talo plano e adnato saxícola, margens eciliadas, sorais marginais lineares interrompidos, em parte nos ápices de pequenas lacínulas, a submarginais subcapitados, rizinas agrupadas e esparsas, e medula contendo ácidos graxos (protoliquesterínico, praesorediósico, protopraesorediósico e outros não identificados) e atranorina ( $\mathrm{K}+$ amarelado, $\mathrm{P}$ - ou $\mathrm{P}+$ fraco amarelado).

Embora não seja mencionado em literatura, a presença de pequeninas lacínulas submarginais em alguns trechos do talo ocorre em todos os espécimes aqui estudados. Estas lacínulas são um tanto similares às observadas em espécimes de $P$. dilatatum (Vainio) Hale e $P$. perlatum (Hudson) M. Choisy (Benatti 2005), porém ainda menores, mais sutis e mais escassas, surgindo a partir de trechos muito incisos das margens.

Hale (1971) mencionou a formação de estruturas coralóides pequenas e "subfatiscentes" (i.e., parcialmente decompostas) a partir dos sorais, comparando-os às formadas em $P$. fasciculatum (Vainio) Hale (= Parmelia fasciculata Vainio). Não se observou a formação destas estruturas em nenhum dos espécimes aqui estudados, tendo estes sido comparados ao espécime de $P$. fasciculatum encontrado (Benatti 2005). Em concordância ao que o próprio Hale afirmou em outro trabalho (Hale 1965), o que foi visto em $P$. fasciculatum parece-se mais com estruturas arbusculares de aspecto isidióide do que com os sorais observados nos espécimes de $P$. mordenii.

Fleig (1997) viu o tipo de P. mordenii, e distinguiu $P$. mordenii, $P$. praesorediosum (Nyl.) Hale e $P$. dactylosum Fleig através da comparação de química medular e das características ligadas ao hábito e formação dos sorais. Entretanto, a autora mencionou duas descrições diferentes para os sorais de $P$. mordenii, uma na discussão de $P$. praesorediosum e outra na de Parmotrema dactylosum (em Fleig 1997, como Parmotrema sp. 1).

Nos comentários de $P$. praesorediosum, Fleig (1997) mencionou que $P$. mordenii difere da primeira por ter talo mais aderido, mais espesso e outra química, não fazendo uma distinção dos sorais e dos sorédios (que supomos, portanto, serem idênticos segundo seu conceito), comparando-a também à Parmotrema sp.1, que diferiu pela formação de dáctilos laminais que se rompem nas áreas centrais do talo, formando sorédios granulares. Já nos comentários de Parmotrema sp. 1, a autora citou que $P$. mordenii tem sorédios granulares e acrescentes, diferentes portanto do que ela deixou subentendido no comentário sobre $P$. mordenii na discussão de $P$. praesorediosum, cujos sorédios, na descrição desta ultima espécie, possuem outras características.

Spielmann (2005) também teve dúvida sobre o significado do termo "subfatiscente" empregado por Hale ao descrever as estruturas formadas pelos sorais, explicando as definições a que se referem o termo "fatiscente" e que o emprego do termo por Hale (1971) foi talvez incorreto para as estruturas que ele observou em $P$. mordenii.

Spielmann (2005) também descreveu os sorais subcapitados que surgem em $P$. mordenii como aparentemente de origem pustular, similares aos observados no material visto aqui. Conforme o que este autor ponderou sobre as descrições de Hale (1971) e de Fleig (1997), somente com a análise do tipo de $P$. mordenii e de outros materiais atribuídos a espécie seria possível esclarecer a dúvida sobre qual é realmente a amplitude da variação encontrada no 
formato dos sorais.

Segundo Hale (1971) e conforme averiguamos neste trabalho, $P$. praesorediosum é a espécie morfológica e quimicamente mais próxima a $P$. mordenii, sendoqueestaespécieéinclusive aceitacomo sinônimo da primeira por Krog \& Swinscow (1981).

Krog \& Swinscow (1981) afirmaram terem encontrado espécimes tanto corticícolas como saxícolas de reação $\mathrm{K}+$ amarelada na medula, que foram atribuídos por eles a $P$. praesorediosum, citando que os outros caracteres apontados por Hale (1971) para a separação das espécies eram provavelmente variações subordinadas aos substratos. Entretanto, os espécimes de $P$. mordenii e de $P$. praesorediosum coletados no litoral apresentam diferenças bem distintas, em concordância àquelas afirmadas por Hale (1971) para a separação das espécies.

Conforme observamos, talos de $P$. praesorediosum tendem a serem menos acinzentados, mais membranáceos e de superfície menos rachada, com sorais marginais de formato mais para labriforme ou crescente, formados por sorédios de granulação mais fina, além de não apresentarem atranorina ( $\mathrm{K}+$ amarelado) na medula, o que os distinguem claramente dos talos de $P$. mordenii.

Embora seja citado em literatura que $P$. praesorediosum possa ocorrer também sobre substratos rochosos (Hale 1965, Krog \& Swinscow 1981, Fleig 1997), a espécie é mais facilmente encontrada sobre córtices arbóreos. Nenhum espécime corticícola ou saxícola analisado aqui apresentou sequer uma sutil reação positiva aos testes de $\mathrm{K}$, enquanto que todos os espécimes saxícolas atribuídos por nós a $P$. mordenii apresentam medula $\mathrm{K}+$ amarelado.

A diferenciação de $P$. praesorediosum e $P$. mordenii com base nas diferenças da preferência de substrato e pela química medular é aceita também por Sipman (2004).

Outra diferença notada é que os talos de P. mordenii têm as margens inferiores sempre de coloração marrom, mesmo quando em lobos sorediados.

Embora Nash \& Elix (2002) mencionem que há diferença entre os tipos de ácidos graxos encontrados nas medulas de $P$. praesorediosum e de $P$. mordenii, percebemos que vários, incluindo os ácidos praesorediósico, protopraesorediósico e caperático, foram encontrados nos espécimes de ambas as espécies, conforme vimos por comparação em CCD.

Outras espécies de Parmotrema de margens sorediadas, como $P$. dilatatum (Vainio) Hale e $P$. perlatum (Hudson) M. Choisy diferem por serem corticícolas e pela química medular, composta por ácidos protocetrárico e equinocárpico em $P$. dilatatum ( $\mathrm{K}+$ amarelo, $\mathrm{KC}+$ róseo, $\mathrm{P}+$ alaranjado) e por ácido estíctico (K+ amarelado, $\mathrm{P}+$ alaranjado) em $P$. perlatum. Esta última espécie tem ainda margens ciliadas, e sorais capitados de disposição peculiar, como um "colar de pérolas" (Benatti 2005).

\section{Parmotrema praesorediosum (Nyl.) Hale, Phytologia} 28(4): $338.1974 \equiv$ Parmelia praesorediosa Nyl. Sert. Lich. Trop. Labuan Singapore 18: 1891. Tipo: SINGAPURA. Almquist (holótipo H-Nyl 35547 n.v.).

Figuras $4 \mathrm{a}, \mathrm{b}$

Talo lobado a sublobado, cinza esverdeado a pardo quando em herbário, de até $20,0 \mathrm{~cm}$ diâm., membranáceo a submembranáceo, corticícola, ramulícola ou saxícola; lobos de ramificação irregular, (1,0-)2,0-7,5(-9,5) mm larg., de contíguos a pouco sobrepostos lateralmente, de adnatos a pouco adnatos tornando-se mais elevados em direção ao centro conforme ficam sorediados, de adpressos a pouco adpressos, os ápices subarredondados, de subplanos a subcôncavos ou raramente revolutos, as margens lisas quando próximas aos ápices e nas partes distais, tornando-se subcrenadas ou crenadas em direção ao centro, de subplanas a ascendentes, subonduladas a onduladas, tornando-se revolutas ou involutas quando sorediadas, inteiras, de superfície contínua e lisa nas partes distais tornando-se irregularmente quebrada e rugosa nas partes velhas, principalmente no centro; lacínulas ausentes, raramente surgindo alguns lóbulos jovens, distribuídos esparsamente pelas margens; máculas ausentes a distintas embora escassas, lineares, laminais ocasionais, às vezes originando quebras; cílios ausentes. Sorais marginais, geralmente labriformes, em formato de crescente ou raramente subcapitados, tornando-se em parte lineares e mais contínuos por coalescência, raramente surgindo laminais ou submarginais subcapitados; sorédios farinhosos a subgranulares. Pústulas e isídios ausentes. Medula branca, sem pigmentações. Lado de baixo negro, lustroso, de liso a rugoso ou pouco venado; margem normalmente marrom a marrom clara, variando para creme, branca, negra ou variegada quando sob lobos sorediados, lustrosa, 0,5 $5,0(-8,0) \mathrm{mm}$ larg., atenuada quando marrom a nítida quando creme ou branca, de lisa a rugosa ou venada, nua; rizinas em geral concoloridas, às vezes mais 
claras ou negras de ápices brancos, simples, raramente aglutinadas, $0,1-0,5(-1,3) \times$ ca. $0,05(-0,10) \mathrm{mm}$, de escassas a frequientes, agrupadas, mais comuns próximas das margens e mais esparsas no centro. Apotécios côncavos a quase planos, 0,3-5,4 mm diâm., laminais, subpedicelados, margem lisa, tornando-se sorediada quando mais velhos, anfitécio e pedicelo lisos a pouco rugosos quando mais velhos; disco marrom, não pruinoso, imperfurado; ascósporos elipsóides ou raramente subglobosos (11,0-)16,0-22,5 × 7,511,5 $\mu \mathrm{m}$, epispório 1,0-1,5(-2,0) $\mu \mathrm{m}$. Picnídios escassos, submarginais, de ostíolos negros; conídios sublageniformes a lecitiformes, 4,0-8,0 $\times$ ca. 1,0 $\mu \mathrm{m}$.

Testes de coloração e substâncias de importância taxonômica: córtex superior $\mathrm{K}+$ amarelo, UV(atranorina); medula $\mathrm{K}-, \mathrm{C}-, \mathrm{KC}-, \mathrm{P}-, \mathrm{UV}-$ (ácidos caperático, protoliquesterínico, praesorediósico, e um outro ácido graxo não identificado situado entre os ácidos praesorediósico e protoliquesterínico na placa cromatográfica, talvez ácido protopraesorediósico).

Distribuição: Pantropical. Oceania, Ásia, África, América do Norte, América Central, Caribe e América do Sul. Brasil: BA, MG, MS, PR, RJ, RS, SC e SP (Elix 1994, Hale 1965, Louwhoff \& Elix 1999, Krog \& Swinscow 1981, Swinscow \& Krog 1988, Osorio 1992, Lynge 1914, como o sinônimo Parmelia capitata, Fleig \& Riquelme 1991, Fleig 1997, Marcelli 1991, Benatti 2005, Divakar \& Upreti 2005, Donha 2005, Feuerer 2005, Jungbluth 2006).

Material estudado: BRASIL. São PAUlo: Iguape, Barra do Ribeira, entre o "Rio" Suamirim e o oceano, vegetação de duna posterior próximo da foz do rio, 21 VII-1989, M.P. Marcelli \& O. Yano 6937 (SP); idem, quintal no fundo de residência a ca. $50 \mathrm{~m}$ do rio, 22VII-1989, M.P. Marcelli \& O. Yano 7137(SP); idem, 22-VII-1989, M.P. Marcelli \& O. Yano 7139 (SP). Ilha Comprida, área central da ilha, parte de trás da residência da família Kitaura, 2-IV-2004, M.N. Benatti et al. 1750 (SP). Itanhaém, Bairro Cidade Santa Júlia, Km 116,5 da Rodovia Padre Manoel da Nóbrega, ca. $500 \mathrm{~m}$ da praia, quintal de residência próximo da mata de restinga, 1-IV-1988, M.P. Marcelli \& L.R. Fontes 2421 (SP); idem, Bairro Nova Itanhaém, ca. 5 Km do centro da cidade, à $200 \mathrm{~m}$ da praia, terreno baldio com algumas velhas árvores nativas, 17-XII-1989, M.P. Marcelli \& O. Yano 4715 (SP); idem, Praia da Enseada, do lado esquerdo da foz do Rio Itanhaém, 23-V-1994, M.P. Marcelli \& A.E. Luchi 27231 (SP); idem, Balneário Santa Cruz, próximo à divisa de municípios entre Itanhaém e Peruíbe, mata de restinga baixa ca. $500 \mathrm{~m}$ da praia, terreno baldio em área loteada, 14-I-2004, M.N. Benatti et al. 1692 (SP). Peruíbe, margem do Rio Guaraú, nas proximidades da foz, Base da Faculdade de Ciência e Tecnologia Santa Cecília, 24-VII-1988, M.P. Marcelli 3937 (SP); idem, 24-VII-1988, M.P. Marcelli 3941 (SP); idem, 24-VII-1988, M.P. Marcelli 3942 (SP); idem, 24-VII-1988, M.P. Marcelli 3943 (SP); idem, 24VII-1988, M.P. Marcelli 3944 (SP); idem, 24-VII1988, M.P. Marcelli 3945 (SP); idem 24-VII-1988, M.P. Marcelli 3961(SP); idem, 24-VII-1988, M.P. Marcelli 4000 (SP); idem, Reserva Ecológica JuréiaItatins, Núcleo Guarauzinho, no sopé da Serra do Mar, no barranco nas proximidades da sede, 26-VII1993, M.P. Marcelli \& O. Yano 23687 (SP); idem, no lado esquerdo da desembocadura do Córrego da Água Fria, 28-VII-1993, M.P. Marcelli \& O. Yano 23759 (SP); idem, Balneário Santa Cruz, na divisa de municípios entre Itanhaém e Peruíbe, mata de restinga baixa em terrenos baldios de área sendo loteada a $50 \mathrm{~m}$ da praia, 14-I-2004, M.N. Benatti et al. 1728 (SP). Praia Grande, Bairro Cidade Ocean, ca. $1 \mathrm{~km}$ após a estátua de Iemanjá, $2 \mathrm{Km}$ da de Netuno, em direção à Mongaguá, terreno entre a praia e a estrada com resíduo de vegetação de duna posterior mata de restinga, 15-VII-1988, M.P. Marcelli \& L.Y. Nagaoka 3467 (SP); idem, 15-VII-1988, M.P. Marcelli \& L.Y. Nagaoka 3473 (SP); idem, ao lado da rodovia, mata de restinga arbustiva, 26-IX-1992, M.P. Marcelli \& O. Yano 14234 (SP); idem, praça gramada a ca. $500 \mathrm{~m}$ da praia, 8-I-1989, M.P. Marcelli 4115 (SP); idem, zona urbana, velhas árvores ao longo da Avenida General Mallet perto da Fortaleza de Itaipu, 27-IX-1992, M.P. Marcelli \& O. Yano 14358 (SP); idem, zona urbana, próximo da rodovia na entrada da cidade, mata escura na beira de canais naturais, 20-V-1994, M.P. Marcelli 27192 (SP); idem, 20-V1994, M.P. Marcelli 27199 (SP); idem, 20-V-1994, M.P. Marcelli 27209 (SP); idem, Jardim Real, zona urbana, em calçada em frente à residência, 15-XII2003, M.N. Benatti \& M.P. Marcelli 1641 (SP); idem, 15-XII-2003, M.N. Benatti \& M.P. Marcelli 1642 (SP); idem, 15-XII-2003, M.N. Benatti \& M.P. Marcelli 1646 (SP); idem, estrada de terra na beira da mata úmida de restinga ca. $1,5 \mathrm{Km}$ da praia, 15-XII-2003, M.N. Benatti \& M.P. Marcelli 1645 (SP). São Sebastião, Centro de Biologia Marinha (CEBIMAR) da USP, no morro ao lado esquerdo do refeitório, 18-III-1988, M.P. Marcelli 2048 (SP); idem, 18-III-1988, M.P. Marcelli 2062 (SP); idem, no morro próximo à escada para o auditório, 18-III1988, M.P. Marcelli 2069 (SP); idem, 18-III-1988, 
M.P. Marcelli 2071 (SP); idem, 18-III-1988, M.P. Marcelli 2073 (SP); idem, na beira do caminho para a saída, 18-III-1988, M.P. Marcelli 2086 (SP); idem, 18-III-1988, M.P. Marcelli 2087(SP); idem, 18-III1988, M.P. Marcelli 2166 (SP); idem, 18-III-1988, M.P. Marcelli 2170 (SP); idem, 18-III-1988, M.P. Macelli 2171 (SP); idem, à $10 \mathrm{~m}$ da praia, 18-III-1988, M.P. Marcelli 2186 (SP); idem, próximo ao cordão de areia que liga a Ponta do Baleeiro ao continente, 19-III-1988, M.P. Marcelli 2219 (SP); idem, morro entre a Praia do Segredo e a Praia do Cabelo Gordo de Dentro, propriedade do Dr. Sawaya, 19-III-1988, M.P. Marcelli 2316 (SP), idem, 19-III-1988, M.P. Marcelli 2318 (SP). Ubatuba, Ilha Anchieta, mata de restinga, em local aberto, 22-XI-2003, L.S. Canêz \& A.A. Spielmann 591 (SP); idem, na beira da praia, 22-XI-2003, L.S. Canêz \& A.A. Spielmann 589 (SP); idem, costão rochoso, 23-XI-2003, L.S. Canêz \& A.A. Spielmann 604 (SP).

Parmotrema praesorediosum é uma das espécies mais facilmente encontradas na localidade de estudo, caracterizada pelo talo aplanado, de margens sorediadas e eciliadas, córtex inferior com agrupamentos esparsos de rizinas, e medula contendo apenas ácidos graxos (todos os testes negativos). O formato labriforme ou de crescente dos sorais é típico, e ao coalescerem lateralmente e tornarem-se mais contínuos, estes aumentam gradativamente a sinuosidade das margens.

O tamanho dos ascósporos encontrados nos espécimes do litoral condiz com o mencionado por Hale (1965), e o dos conídios com o mencionado por Fleig (1997) e por Spielmann (2005).

Uma peculiaridade observada nos espécimes estudados foi o surgimento de rizinas de ápices brancos, o que também foi constatado por Ribeiro (1998), Donha (2005) e Spielmann (2005).

A presença do ácido caperático entre os ácidos graxosdestaespéciefoimencionadanaliteraturaapenas por Hale (1965), Awasthi (1976) e Spielmann (2005).

Uma espécie similar, Parmotrema ciliiferum Hale, também apresenta sorais marginais e reações negativas na medula, apresentando outro conjunto de ácidos graxos, incluindo o ácido constipático (comparados em CCD). Esta espécie difere de $P$. praesorediosum também pela formação de pequenas lacínulas marginais, com sorais lineares apicais, pelas margens bastante ciliadas com cílios relativamente longos (até $3,5 \mathrm{~mm}$ ), e pelos conídios baciliformes curtos $(3,0-5,0 \mathrm{~mm})$. As rizinas de $P$. ciliiferum são mais homogeneamente distribuídas, ainda que também escassas, e sempre são concoloridas ao córtex inferior.

Parmotrema mordenii (Hale) Hale foi aceita por Krog \& Swinscow (1981) como sinônimo de P. praesorediosum. A espécie tem sorais marginais de formato e disposição semelhante, porém algo como intermediários entre os de $P$. praesorediosum e os vistos em $P$. dilatatum ou $P$. gardneri (Dodge) Sérusiaux e (ver descrição e comentários em $P$. mordenii).

Apesar dos apontamentos feitos por Krog \& Swinscow (1981) para a sinonimização, o material estudado atribuído por nós à $P$. mordenii está em concordância com o mencionado por Sipman (2004) e Spielmann (2005), e tem reação K+ amarela constante e evidentemente na medula, atribuída à presença de atranorina. Outro motivo para a concordância está no fato de que os talos de P. mordenii encontrados são todos saxícolas.

Parmotrema dilatatum (Vainio) Hale difere de $P$. praesorediosum pelos sorais subcapitados, também situados nos ápices de lacínulas, em parte marginais lineares e irregulares, pela química medular que apresenta ácidos equinocárpico e protocetrárico $(\mathrm{K}+$ amarelado, $\mathrm{KC}+$ róseo, $\mathrm{P}+$ alaranjado, UV-), e também pela presença ocasional de traços de ácido úsnico no córtex superior (Benatti 2005). Parmotrema gardneri (Dodge) Sérusiaux também difere de $P$. presorediosum pelo formato e disposição dos sorais similares aos de $P$. dilatatum, pelo talo coriáceo, e por apresentar ácido protocetrárico $(\mathrm{KC}+$ róseo, $\mathrm{P}+$ alaranjado) medular (Benatti 2005).

Parmotrema austrosinense (Zahlb.) Hale difere pelos sorais lineares contínuos, de granulação sempre fina, pela margem inferior constantemente clara e por apresentar ácido lecanórico $(\mathrm{C}+\mathrm{e} \mathrm{KC}+$ avermelhados) na medula.

Parmotrema subochraceum Hale difere por apresentar ácido protocetrárico $(\mathrm{KC}+$ róseo, $\mathrm{P}+$ alaranjado) medular e pigmento alaranjado $\mathrm{K}+$ avermelhado escuro visível em hifas distintas por toda a porção inferior da medula (Benatti 2005, Benatti \& Marcelli 2010).

Parmotrema soredioaliphaticum Estrabou \& Adler (1998) apresenta ácidos graxos ainda desconhecidos, e sorais surgindo sempre nos ápices de dáctilos, em geral laminais.

Alguns espécimes encontrados, citados no material estudado, mas que não foram incluídos na descrição de $P$. praesorediosum devido a algumas divergências morfológicas (e em menor 
grau químicas) deixaram dúvidas sobre se são variações intra-específicas ou de espécies distintas próximas de $P$. praesorediosum. A elucidação destas dúvidas necessitaria da análise do material tipo de $P$. praesorediosum e coleta de mais material que compartilhasse as características dos espécimes em questão, para uma comparação das características químicas e morfológicas.

\section{Agradecimentos}

Os autores agradecem à assessoria pelas contribuições e revisão do trabalho e ao Conselho Nacional de Desenvolvimento Científico e Tecnológico $(\mathrm{CNPq})$ pelas bolsas de mestrado e de pesquisa concedidas, respectivamente, ao segundo e primeiro autores.

\section{Literatura citada}

Asahina, Y. \& Shibata, S. 1954. Chemistry of Lichen Substances. Japan Society for the Promotion of Science, Tóquio.

Awasthi, D.D. 1976. Lichen genus Parmelia in India I - Subgenera Parmelia and Amphigymnia. Biological Memoirs 1: 155229.

Benatti, M.N. 2005. Os gêneros Canomaculina, Parmotrema e Rimelia (Parmeliaceae, Ascomycetes) no litoral centro-sul do estado de São Paulo. Dissertação de Mestrado, Instituto de Botânica, São Paulo.

Benatti, M.N. \& Marcelli, M.P. 2008. Espécies de Parmotrema (Parmeliaceae, Ascomycetes) com máculas reticulares do litoral centro-sul do Estado de São Paulo, Brasil. Hoehnea 35: 75-90.

Benatti, M.N. \& Marcelli, M.P. 2010. Espécies de Parmotrema (Parmeliaceae, Ascomycota) com medula pigmentada do litoral centro-sul do Estado de São Paulo. Hoehnea 36: $597-$ 612.

Brodo, I.M., Sharnoff, S.D. \& Sharnoff, S. 2001. Lichens of North America. Yale University Press, New Haven.

Bungartz, F. 2001. Analysis of lichen substances. http://ces.asu.edu/ASULichens/plb 400/ laboratory/chemistry/tlc.html (acesso em 01/10/2004).

Canêz, L.S. 2005. A família Parmeliaceae na localidade de Fazenda da Estrela, Município de Vacaria, Rio Grande do Sul, Brasil.
Dissertação de Mestrado, Instituto de Botânica, São Paulo.

Divakar, P.K. \& Upreti, D.K. 2005. Parmelioid lichens in India (A revisionary study). Bishen Singh Mahendra Pal Singh, Dehra Dun.

Donha, C.G. 2005. Os gêneros Canomaculina, Parmotrema e Rimelia (Ascomycota Liquenizados) na Área de Proteção Ambiental de Guaraqueçaba, Paraná, Brasil. Dissertação de Mestrado, Universidade Federal do Paraná, Curitiba.

Eliasaro, S. 2001. Estudio taxonomico y floristico sobre las Parmeliaceae sensu stricto (Ascomycota liquenizados) del Segundo Planalto del Estado de Paraná, Brasil. Tese de Doutorado, Universidad de Buenos Aires, Buenos Aires.

Eliasaro, S. \& Donha, C.G. 2003. The genera Canomaculina and Parmotrema (Parmeliaceae, lichenized Ascomycota) in Curitiba, Paraná State, Brazil. Revista Brasileira de Botânica 26: 239-247.

Elix, J.A. 1994. Parmotrema. In: A.E Orchard \& C. Grgurinovic (eds.). Flora of Australia, Lichens. Introduction, Lecanorales 2. Australia Government Publishing Service, Canberra, v. 55, pp. 140-162.

Esslinger, T.L. \& Egan, R.S. 1995. A sixth checklist of the lichen-forming, lichenicolous, and allied fungi of the continental United States and Canada. The Bryologist 98: 467-549.

Estrabou, C. \& Adler, M.T. 1998. Two new species of Parmotrema (Parmeliaceae, Lichenized Ascomycotina) from Argentina. Mycotaxon 65: 131-136.

Feuerer, T.E. (ed.) 2005. Checklists of lichens and lichenicolous fungi. Versão I Junho de 2006. In http://www.checklists.de (acesso em 09.2005).

Fink, B. 1905. How to collect and study lichens. The Bryologist 8: 22-27.

Fleig, M. 1997. Os gêneros Parmotrema, Rimelia e Rimeliella (Lichenes-Ascomycota, Parmeliaceae) no Rio Grande do Sul, Brasil. Tese de Doutorado, Universidade de São Paulo, São Paulo.

Fleig, M. \& Riquelme, I. 1991. Liquens de Piraputanga, Mato Grosso do Sul, Brasil. Acta Botanica Brasilica 5: 3-12.

Galloway, D.J. 1985. Flora of New Zealand - lichens. Government Printer Wellington.

Galloway, D.J. 2007. Flora of New Zealand Lichens. Revised second edition including lichen-forming and lichenicolous fungi. V. 1 and 2. Manaaki Whenua Press, Lincoln. 
Hale, M.E. 1965. A Monograph of the Parmelia subgenus Amphigymnia. Contributions from the United States National Herbarium 36: 193-358.

Hale, M.E. 1971. Morden-Smithsonian expedition to Dominica: The Lichens (Parmeliaceae). Smithsonian Contributions to Botany 4: 1-25.

Hale, M.E. 1974. New combinations in the lichen genus Parmotrema Massalongo. Phytologia 28: 334-339.

Hale, M.E. 1977. New species in the lichen genus Parmotrema Mass. Mycotaxon 5: 432-448.

Hale, M.E. 1979. How to know the Lichens. The Pictured-Key Nature Series. W.C. Brown, Dubuque.

Hale, M.E. 1990. New species of Parmotrema (Ascomycotina: Parmeliaceae) from Tropical America. Bibliotheca Lichenologica 38: 109-119.

Huneck, S. \& Yoshimura, I. 1996. Identification of Lichen Substances. Springer Verlag, Berlin.

Jackson, D.W. \& Hopkins, A.W. 1980. New additions to the lichen flora of Texas and the United States. The Bryologist 83: 532-533.

Jungbluth, P. 2006. A família Parmeliaceae (fungos liquenizados) em fragmentos de cerrados do Estado de São Paulo. Dissertação de Mestrado, Instituto de Botânica, São Paulo.

Krog, H. \& Swinscow, T.D.V. 1981. Parmelia subgenus Amphigymnia (lichens) in East Africa. Bulletin of British Museum of Natural History Botany 9: 143-231.

Kurokawa, S. 1974. Four new species of Parmelia from Brazil. Bulletin of the Natural Science Museum of Tokyo 17: 297-300.

Louwhoff, S.H.J.J. \& Elix, J.A. 1999. Parmotrema and allied lichen genera in Papua New Guinea. Bibliotheca Lichenologica 73: 1-152.

Lynge, B. 1914. Die Flechten der ersten Regnellschen Expedition. Die Gattungen Pseudoparmelia gen. nov. und Parmelia Ach. Arkiv för Botanik 13: 1-172.

Marcelli, M.P. 1991. Aspects of the foliose lichen flora of the southern-central coast of São Paulo State, Brazil. In: D.J. Galloway (ed.). Tropical lichens: their systematics, conservation, and ecology. Systematics Association Special v. 43. Clarendon Press, Oxford, pp. 151-170.

Marcelli, M.P. 2005. Checklist of Brazilian lichens. Publicação na Internet, pela Universität Hamburg - Institut für Allgemeine Botanik, dentro do programa South American Lichens Online, em http://www.rra.uni-hamburg.de/biologie/ialb/ herbar/brazi_f2.htm (acesso em 01.03.2005).
Nash III, T.H. \& Elix, J.A. 2002. Parmotrema. In: T.H. Nash III, B.D. Ryan, C. Gries \& F. Bungartz (eds.). Lichen Flora of the greater Sonoran Desert Region. v. 1. Lichens Unlimited, Arizona State University, Tempe, pp. 318-329.

Orange, A., James, P.W. \& White, F.J. 2001. Microchemical methods for the identification of lichens. The British Lichen Society, London.

Osorio, H.S. 1992. Contributions to the lichen flora of Uruguay XXV. Lichens from Sierra San Miguel, Rocha Department. Boletín de la Sociedad Argentina de Botánica 28: 37-40.

Ribeiro, C.H. 1998. A família Parmeliaceae (Ascomycota liquenizados) em Regiões montanhosas dos estados de Minas Gerais, Rio de Janeiro e São Paulo. Dissertação de Mestrado, Universidade de São Paulo, São Paulo.

Sipman, H.J.M. 2004. Mason Hale's key to Parmotrema, revised edition: key to wide-lobed parmelioid species occurring in Tropical America (genera Canomaculina, Parmotrema, Rimelia, Rimeliella). Em http://www.bgbm.org/sipman/ keys/neoparmo.htm (acesso em 01.07. 2005).

Spielmann, A.A. 2005. A família Parmeliaceae (fungos liquenizados) nos barrancos e peraus da encosta da Serra Geral, no Vale do Rio Pardo, Rio Grande do Sul, Brasil. Dissertação de Mestrado, Instituto de Botânica, São Paulo.

Swisncow, T.D.V. \& Krog, H. 1988. Macrolichens of East Africa. British Museum of Natural History, London.

Vainio, E.A. 1890. Étude sur la classification naturelle et la morphologie des Lichens du Brésil, pars prima. Acta Societatis pro Fauna et Flora Fennica 7: i-xxix, 1-247.

Vareschi, V. 1962. Resultados liquenologicos de excursiones efectuadas en Venezuela. II. Acta Biologica Venezuelica 3: 201-232.

Walker, J.W. \& James, P.W. 1980. A revised guide to microchemical techniques for the identification of lichen products. Bulletin of the British Lichen Society 46 (supl.): 13-29.

White, F.J. \& James, P.W. 1985. A new guide to microchemical techniques for the identification of lichen substances. British Lichen Society Bulletin 57 (supplement): 1-41.

Winnem, B. 1975. Parmelia subgenus Amphigymnia in Ethiopia. Norwegian Journal of Botany 22: 139-166.

Zahlbruckner, A. 1908. Beiträge zur Flechtenflora Brasiliensis. Bulletin de L'Herbier Bissier, 2me série, 7: 459-468. 